\title{
Letrônica
}

\section{A poesia portuguesa no Samba de Roda do Recôncavo Baiano}

\section{The Portuguese poetry in the "Samba de Roda" of the Recôncavo Baiano (Brazil)}

Ricardo Mendes Mattos Universidade de São Paulo, Laboratório de Estudos em Psicologia da Arte, São Paulo, SP, Brasil

Doutor em Psicologia Social da Arte pela influências do cancioneiro popular português nos cantos tradicionais da cultura brasileira. E-mail: ricardomendesmattos@gmail.com
RESUMO: Apresenta-se exemplos da influência da poesia popular portuguesa nos versos cantados no Samba de Roda do Recôncavo Baiano, a partir da comparação entre versões do cancioneiro popular português e gravações fonográficas do Samba de Roda. Conclui-se que a poesia popular portuguesa fornece não apenas elementos poéticos referentes a estrofe e a rima, como reconhecido por estudiosos, mas também conteúdos verbais em versos idênticos.

Palavras-chave: Cultura tradicional; Samba de Roda; Cancioneiro popular português; Cultura afro-brasileira; Cultura luso-brasileira.

ABSTRACT: Examples of the influence of Portuguese popular poetry in the verses sung in the "Samba de Roda" of the Recôncavo Baiano (Brazil) are presented, based on the comparison between versions of the Portuguese popular songbook and phonographic recordings of "Samba de Roda". It is concluded that Portuguese popular poetry provides not only poetic elements referring to stanza and rhyme, as recognized by scholars, but also verbal contents in identical verses.

Keywords: Popular culture; "Samba de Roda"; Portuguese popular songbook; Afro-Brazilian culture; Luso-Brazilian culture. 
$\mathrm{D}$ acordo com o Instituto do Patrimônio Histórico e Artístico Nacional (IPHAN, 2006a), o samba de roda é uma expressão cultural festiva que reúne manifestações de música, de dança e de poesia. Dispostos em roda, os sambadores utilizam, principalmente, a viola e o pandeiro, entoando estrofes que são respondidas em coro e intercaladas por outras extraídas do manancial do cancioneiro tradicional da região. As rodas ocorrem em festas típicas do catolicismo popular ou no interior de tradições religiosas afro-brasileiras. Embora o samba de roda ocorra em todo o estado da Bahia, mantém raízes tradicionais profundas na região conhecida como Recôncavo Baiano, área geográfica que compreende diversos municípios à margem da Baía de Todos os Santos, similares cultural e economicamente (historicamente caracterizados pela monocultura de cana-de-açúcar e fumo, mediante exploração do trabalho escravo afrodescendente).

No ano de 2004, o samba de roda do Recôncavo Baiano é reconhecido como Patrimônio Cultural do Brasil, pelo IPHAN. No ano seguinte, é condecorado com o título de Obra-Prima do Patrimônio Oral e Imaterial da Humanidade, concedido pela Unesco (United Nations Educational, Scientific and Cultural Organization) (IPHAN, 2006a).

O reconhecimento mundial do samba de roda desencadeia inúmeros registros audiovisuais e fonográficos dessa expressão cultural, organiza políticas públicas de salvaguarda e incentiva a realização de diversos estudos científicos sobre o tema.

Tais estudos, a começar pelo próprio Dossiê do IPHAN sobre samba de roda do Recôncavo Baiano (2006a), ressaltam suas raízes africanas. Essa expressão ritual teria sido cultuada por africanos escravizados no Estado da Bahia, como sinal evidente de sua criatividade na renovação de tradições ancestrais. Tal reinvenção está relacionada ao encontro entre elementos da matriz africana com aqueles de influência europeia, especialmente ligados aos instrumentos musicais presentes no samba (como a viola e o pandeiro) e a poesia portuguesa. Uma passagem do Dossiê utiliza o termo "mesclar" para explicar essa relação entre os legados africano e português:

O samba de roda, desde antigos relatos, traz como suporte determinante tradições culturais transmitidas por africanos escravizados no Estado da Bahia. Essas tradições se mesclaram de maneira singular a traços culturais trazidos pelos portugueses, como os instrumentos mencionados acima [viola e pandeiro], e à própria língua portuguesa e elementos de suas formas poéticas (IPHAN, 2006a, p. 24)

A inventividade afro-brasileira inclui, portanto, uma incorporação bastante original das tradições lusitanas, em especial de dois elementos: os instrumentos musicais e a forma poética. Quanto à reinvenção original da maneira de tocar a viola, trabalhos como aquele de Cássio Nobre detalham as formas como as comunidades afro-brasileiras “... criaram uma forma africanizada de expressar a antiga maneira portuguesa de tocar este instrumento" (NOBRE, 2009 - grifos do original).

No que se refere à poesia cantada no samba, acredita-se ter havido um processo similar: "O mesmo se pode dizer da parte poética do samba, cantada em língua portuguesa, com corte estrófico e rítmico português, mas com emissão vocal e conteúdo verbal absolutamente associados à cultura dos afrodescendentes do Recôncavo" (IPHAN, 2006a, p. 73).

Certamente, a estrofe predominante nas canções populares brasileira é a quadra tradicional portuguesa, com o ritmo marcado por rimas terminais entre o segundo e o quarto versos. Autores como Câmara Cascudo (1984, p. 27) notaram a presença da quadra como "redondilha maior de Portugal", assim como enfatizaram sua grande influência na poesia brasileira. Contudo, seria o "conteúdo verbal absolutamente" afrodescendente? Não havendo pesquisas que aprofundem essa questão, convém perguntar: Qual é a influência da poética tradicional lusitana no samba de roda? 
Com o objetivo de responder a essa questão, o presente artigo realiza estudo exploratório sobre a presença de versos portugueses em registros fonográficos do samba de roda do Recôncavo Baiano, cotejando os cantos do samba com as diversas recolhas do cancioneiro popular português. Em outras palavras, buscamos observar como conteúdos verbais absolutamente tradicionais em Portugal são cantados por sambadores e sambadoras, tais como Dona Dalva Damiana, Edith do Prato, Nicinha, Mãe Walquíria, dentre outros.

Desde meados do século XIX, diversos folcloristas têm acumulado dezenas de obras contendo a poesia cantada em inúmeras regiões de Portugal, naquilo que se denomina o cancioneiro popular português. Tais obras compilam, portanto, grande parte da tradição poética lusitana, presente em diversos cantos do Brasil (folia de Reis, congadas, emboladas, cana-verde, jongo, calango, etc). Por outro lado, o grande interesse recente no samba de roda multiplicou dezenas de registros fonográficos, com a gravação de diversas comunidades, sambadores e sambadoras. Assim, realizamos a comparação entre os versos cantados nas gravações e aqueles registrados nos cancioneiros portugueses, chegando a inúmeros versos coincidentes.

Devido à característica exploratória da pesquisa, restringimo-nos a apresentar esses versos semelhantes, deixando para estudos posteriores o aprofundamento da reinvenção poética praticado por afro-brasileiros.

O cotejamento dessas fontes permite afirmar forte presença do legado poético lusitano no coração dessa expressão genuinamente africana da cultura brasileira.

\section{Catolicismo popular, candomblé e samba de roda}

Muitas das comunidades sambadoras desenvolvem uma devoção aos santos e rituais católicos, que se manifesta a partir de expressões tradicionais como folia de Reis, loas e orações. Sabe-se que o contexto de realização do samba de roda esteve vinculado às festas dos dias santos ou ao ritual de folia de Reis, fato que fortalece esse vínculo entre o samba e a fé católica. Nos versos gravados por diversos sambadores e sambadoras há nítido reflexo da incorporação do catolicismo lusitano na composição poética dos sambas.

A comunidade de São Braz, por exemplo, expressa de maneira intensa esse vínculo. Há um verso de chegança comumente cantado pelo Samba Chula:

$$
\begin{aligned}
& \text { Deus vos salve casa santa } \\
& \text { Onde Deus fez a morada } \\
& \text { Onde mora o cálix bento } \\
& \text { E a hóstia consagrada (SAMBA..., 2010). }
\end{aligned}
$$

Tal verso é idêntico àquele coletado por Teófilo Braga e está presente em grande variedade de cantos tradicionais praticados em diversas partes do Brasil:

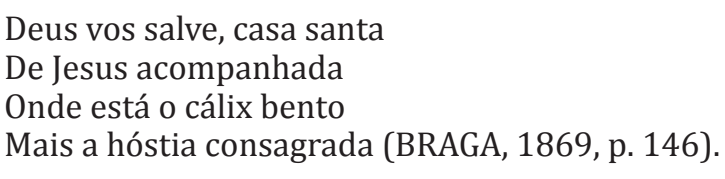

Deus vos salve, casa santa

De Jesus acompanhada

Onde está o cálix bento

Mais a hóstia consagrada (BRAGA, 1869, p. 146).

Trata-se de um verso inicial da folia de Reis no Arquipélago dos Açores. Ao cantar tal estrofe para iniciar sua participação no Festival de Música Womex, o Samba Chula de São Braz traz não apenas a influência poética portuguesa, mas um elemento tradicional no ritual católico: a "chegança" ou os cumprimentos iniciais de um culto, evocando Deus e abençoando a casa em que se canta.

O registro do Samba Chula de São Braz, intitulado Quando eu dou minha risada, há, há (2009), traz ainda uma Reza para Santo Antônio com versos incomuns nos sambas, mas frequentes nas orações luso-brasileiras: 
Botai vossa face

Com olhar propício

Salve os brasileiros

No santo exercício (SAMBA..., 2009)

As palavras empregadas, pouco usuais no linguajar cotidiano, revelam uma fonte ligada às orações da Igreja Católica oficial. Tais versos são cantados também em outras comunidades sambadoras, como no registro santoamarense realizado por Dona Nicinha (2012). Nas aldeias rurais portuguesas, tais devoções, orações e rituais são muito frequentes, deixando claro que os sambadores incorporam, por meio dos versos, elementos fundamentais do convívio social, como a religiosidade e o ritual de canto lusitanos.

Os versos portugueses não estão apenas no catolicismo popular das comunidades afro-brasileiras, mas nos espaços de religiosidade de matriz africana. Aqui há um detalhe importante: os cantos aos orixás, que preservaram os diversos dialetos africanos, conseguiram conservar uma matriz afrodescendente mais precisa; ao passo que os cantos do samba de roda que ocorrem após o culto, que utilizam a língua portuguesa, tendem a incorporar versos do cancioneiro popular lusitano.

Comecemos pelo registro Sambas de Roda e Candomblés da Bahia (s/d), gravação pioneira da JS discos, que se inicia com cantigas rituais de culto aos orixás e depois apresenta alguns sambas.

Uma estrofe clássica, presente nos mais diversos cantos do Brasil ${ }^{1}$, é a seguinte:

Você de lá e eu de cá

E o rio passa no meio

Você de lá dá um suspiro

Eu de cá suspiro e meio (SAMBAS..., s/d).

Por exemplo em Música Popular do Sudeste/Centro-Oeste (v. 3, 1974), Cocos: alegria e devoção (1999), Caiana dos crioulos (2003), Cia. Cabelo de Maria (2007), dentre muitos outros.
Tal verso é muito comum na Bahia, tendo sido registrado em gravações como Folclore Musical Baiano (1971), Ganhadeiras de Itapuã (2015) e Quixabeira (1992). Perece ser uma adaptação de diversos versos similares encontrados no cancioneiro popular português, tal como:

Tu de lá e eu de cá,

Mete-se o rio ao meio.

Eu na fama já sou tua,

Hei-te amar a rio cheio! (NOGUEIRA, 2011a, p. 272).

Não deixa de ser curiosa essa imagem do diálogo entre dois amantes separados por um rio, da mesma forma em que o cancioneiro brasileiro enamora o português, separados também pelas águas do oceano. 0 samba de roda do Recôncavo Baiano parece estabelecer esse diálogo com profundas raízes da cultura brasileira, seja a mãe África do além-mar, seja as comunidades aldeãs portuguesas.

O tema das águas ainda dá ensejo à seguinte quadra:

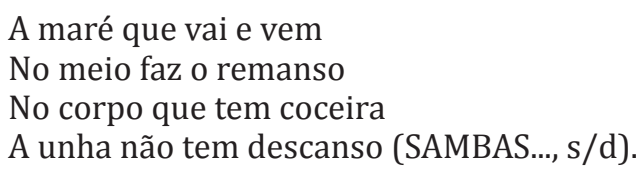

Trata-se de um tema muito comum no cancioneiro popular português. O primeiro dístico está presente em recolhas como aquela do conselho de Baião:

Adeus, ó lugar da Pala,

Onde a água faz remanso;

Onde eu tenho o meu amor

No lugar de Porto Manso (NOGUEIRA, 2011a, p. 34).

Com o mesmo tema e formulação parecida, há a seguinte quadra, registrada por Teófilo Braga $(1869$, p. 15) e também por Neves e Campos (1898, p. 51): 


\section{A ribeira, quando corre}

No meio faz a zoada

Quem tem amores não dorme

O sono da madrugada

Vejam que a zoada ou o remanso, do rio ou do mar, surgem como acontecimento da natureza que serve de comparação à inquietação humana, seja pela coceira, pela paixão ou pela distância do amor.

Outro verso de Sambas de Roda e Candomblés da Bahia é o seguinte:

Eu não falo de mulher

Porque eu dela sou nascido

Não quero que ela diga

Que sou mal agradecido (SAMBAS..., s/d).

Tal composição encontra paralelo em formulações portuguesas, como:

Hei de cantar os teus olhos,

Porque não sou mal mandado,

Não quero que depois digas:

Vai te embora malcriado (OLIVEIRA, 1905, p. 252).

Por fim, há um canto de despedida muito comum em ambos os cancioneiros, brasileiro e português:

Vou-me embora, vou-me embora

Como já disse que vou

Se eu aqui não sou querida

Mas na minha terra eu sou (SAMBAS..., s/d).

Adeus, que me vou embora

Adeus, que embora me vou

Daqui para a minha terra

Que desta terra não sou (NOGUEIRA, 2011a, p. 53).

Se o terreiro do candomblé foi um dos viveiros do samba, inclusive aquele samba carioca florescido na Praça Onze, em terreiros de baianas com Tia Ciata, aí está um exemplo da presença do legado lusitano em um dos principais núcleos de efervescência da cultura afro-brasileira.

\section{Versos portugueses do Samba de Roda}

Passemos agora a uma das sambadoras mais reconhecidas do Recôncavo Baiano:
A maré que enche e vaza
Deixa a praia descoberta
Vai um amor e vem outro
Nunca vi coisa tão certa (PRATO, 2003).

O mesmo ditado, em versos praticamente idênticos, foi recolhido na região portuguesa do Ribatejo, por Alves Redol (1950, p. 164):
Baixa o mar, vasa a maré
Fica a praia descoberta
Vai-se um amor e vem outro
Não há palavra mais certa

A simpatia de atirar uma fruta (limão, laranja) para tirar a sorte do amor é uma tradição portuguesa muito disseminada no Brasil, tal como o famoso bem-me-quer e malmequer com pétalas de flores. Tal costume surge nos seguintes versos:

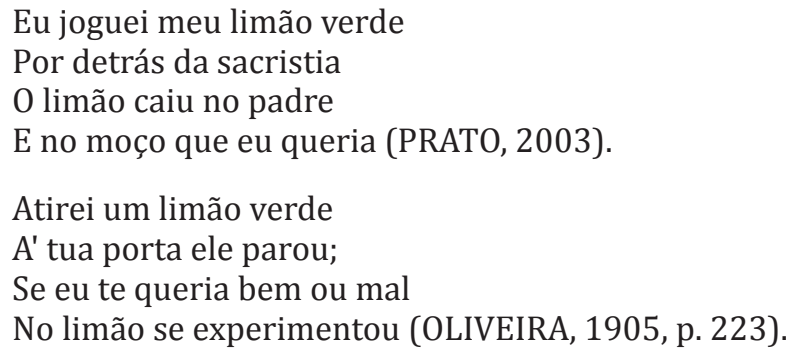


Em ambos os casos, o paradeiro do limão sela o destino do amor daquele que o atirou.

Muitos versos portugueses e brasileiros tematizam o papel dos pais na aceitação ou rejeição dos amores de seus filhos, em um momento histórico em que a opinião dos pais era crucial para o destino dos casamentos. Em Edith do Prato, temos a seguinte estrofe:

$$
\begin{aligned}
& \text { Minha mãe me deu uma surra } \\
& \text { Sexta-feira da paixão } \\
& \text { Quanto mais que ela vice } \\
& \text { O chamego no portão (PRATO, 2003). }
\end{aligned}
$$

Ela se assemelha, na composição e no tema, a versos do cancioneiro popular português como o seguinte:

Minha mãe me deu pancadas,

Puxou-me pelas orelhas.

Por que eu fugia das moças

Como o lobo das ovelhas (OLIVEIRA, 1905, p. 241).

Em ambos, a atitude agressiva da mãe se volta aos comportamentos atrevidos de seus filhos.

Outra tradição portuguesa comum nos cantos brasileiros é aquela do uso de topônimos, ou seja, menções a lugares na composição dos versos, tais como:

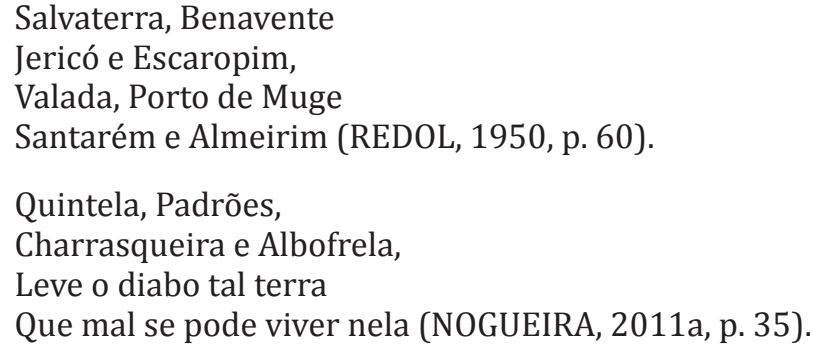

Tal hábito está presente nos seguintes versos, cantados por Edith do Prato e também por Dona Nicinha:

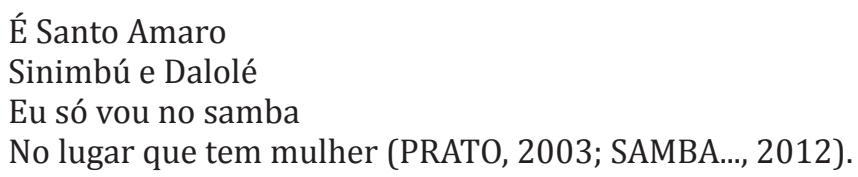

Por fim, há uma faixa de Vozes da Purificação, em que Edith do Prato narra a morte de um boi, que passa a ser repartido entre membros da comunidade:

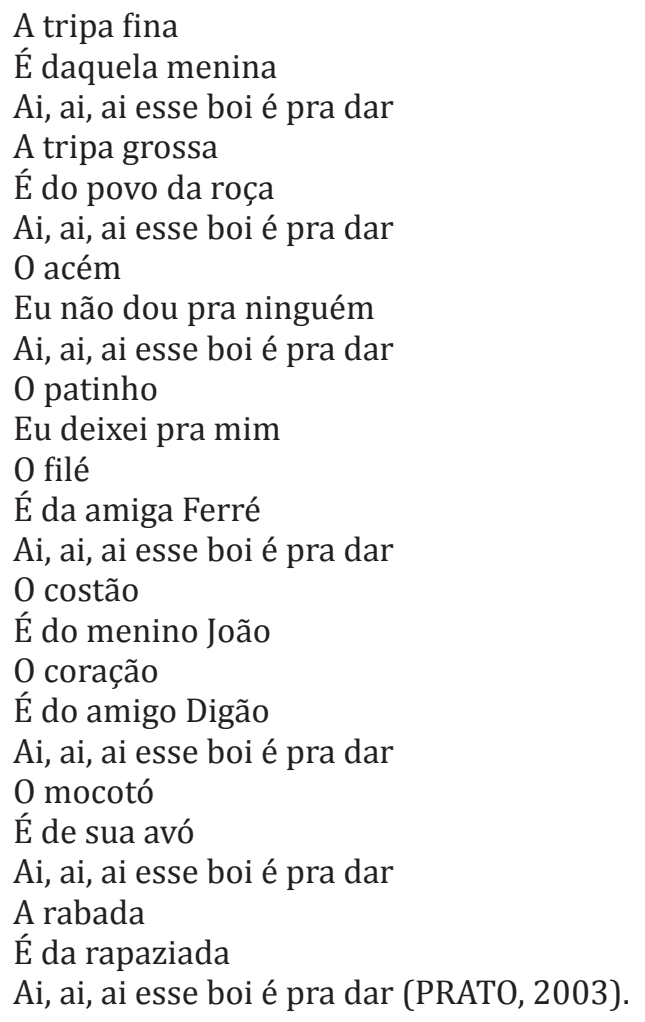


O mesmo episódio é narrado na conhecida canção $O$ Antônio Geraldo, integrante do Cancioneiro de Músicas Populares coletado por Cesar das Neves e Gualdino de Campos (1898, p. 225), muito embora seja proveniente do Sergipe, recolhido por Sílvio Romero (1883, v. I, p. 170). Há versos muito similares, tais como:

\section{A tripa gaitera \\ É de Maria Vieira \\ A tripa mais grossa \\ De Chico da Rocha}

Na região de Cachoeira, há muitos versos que fazem alusão ao vapor de fabricação inglesa que por ali passava. Na voz de Dona Dalva Damiana:

Embarca, meu bem, embarca

Que o vapor já vai largar

O samba é de Cachoeira

E eu sou sambarista (DAMIANA, s/d).

Com alguma variação, a mesma estrofe é também cantada por Dona Nicinha (2012). Tais versos são muito similares a uma estrofe conhecida em diversas regiões de Portugal, como se vê nas coletas de Teófilo Braga (1867, p. 59), Neves e Campos (1893, p. 33), Nogueira (2011a, p. 127) e Cortesão (1914, p. 117):

Quem embarca, quem embarca

Quem vem para o mar, quem vem?

Quem embarca nos meus olhos?

Oh que linda maré tem!

Há outros versos cantados por Dona Dalva que encontram ressonância nas comunidades rurais lusitanas, como, por exemplo:
Riacho sacode pro rio

0 rio sacode pro mar

0 mar que é morada de peixe

Quero ver você sambar (DAMIANA, s/d).

Ó meu amor, anda, anda,

Qu'eu te quero ver andar;

A água corre p'rò rio,

0 rio corre p'rò mar (NOGUEIRA, 2011a, p. 123).

No registro do samba de roda de Mãe Walquíria, outra sambadora baiana, encontramos a seguinte estrofe, muito semelhante a algumas quadras portuguesas:

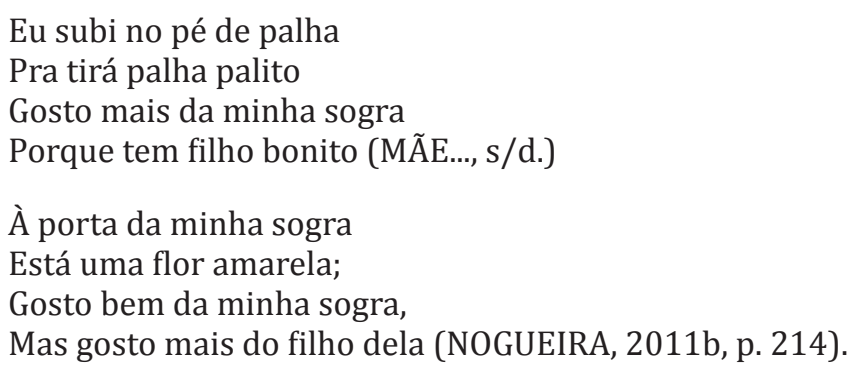

Também um verso clássico, conhecido em diversos cantos do Brasil ${ }^{2}$, é cantado por Mãe Walquíria:

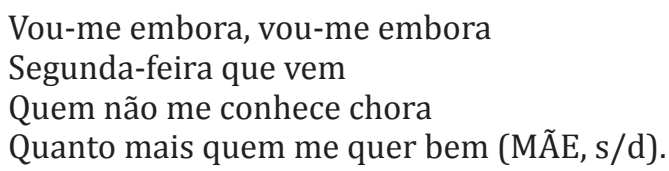

É uma quadra colhida em versões populares do cancioneiro português, a exemplo de:

2 Por exemplo em Música Popular do Norte (v. 2, 1976), Cocos: alegria e devoção (1999), Caiana dos crioulos (2003), Cia. Cabelo de Maria (2007), dentre muitos outros. 
Vou-m'embora, vou-m'embora,

Par'á semana que vem;

Quem me não conhece chora,'

Que fará quem me quer bem (OLIVEIRA, 1905, p. 240).

Há duas estrofes cantadas de maneira idêntica por Dona Nicinha e pelo Samba Chula de São Braz que remetem ao cancioneiro popular português:

Tem um amor que me ama

Outro que me dá dinheiro

Quero que você me diga

Qual é o amor verdadeiro (SAMBA..., 2012).

Tenho um amor que me ama,

Outro que me dá dinheiro,

Outro que me veste e calça,

Esse é o mais verdadeiro (NOGUEIRA, 2011a, p. 221-2).

Menina quando eu te peço

Quando eu torno a te pedir

Na cama que eu me deitar

Tu não deixa outro dormir (SAMBA ..., 2009).

Eu pedi-lh'uma folhinha

Ella disse-me que não,

E tornei-lh"a a pedir

Ella deu-me o seu cordão (OLIVEIRA, 1905, p. 132).

A primeira estrofe é idêntica à sua congênere portuguesa, ao passo que a segunda possui uma forma de dizer e uma formulação poética parecidas.

Estes são os registros mais conhecidos do Samba de Roda, apresentando as comunidades e os sambadores mais consagrados. Contudo, em outras recolhas, também vemos a presença do cancioneiro popular português nessa tradição cultural baiana. Nos documentários Ouça o meu palavreado (2009) e Cantador de Chula (2009), mestre Boião (São Francisco do Conde), assim como Dona Zelita e Dona Ana do Rosário (Saubara) cantam uma estrofe parecida:

Eu me chamo Zé de Rosa

Querido de vosmicê

Assado você não come

Cozido não quer comer

Tal estrofe se observa em versões portuguesas coletadas por Neves e Campos (1895, p. 240) ou Carlos Nogueira (2011b, p. 175):

Meu amor, você tem coisas!

Num no posso entender:

Você assado num come,

Cozido num quer comer

O mesmo Carlos Nogueira coleta no conselho de Baião os versos:

Uma moça pra ser moça,

Há-de ter oito amores:

Dois casados, dois solteiros,

Dois abades, dois doutores (NOGUEIRA, 2011a, p. 106).

Uma mulher assim assanhada é cantada pela sambadora Nega Duda (2008):

Dona Lila

É mulher de sete maridos

Dois na cama, um na lama

Quatro no mato escondido

No registro Samba de Roda do Recôncavo Baiano (1994) ouvimos o seguinte dístico, muito similar a uma quadra portuguesa: 
Foi você quem me ensinou

Namorar que eu não sabia

José me ensinou a amar

Coisa que eu não sabia

Para agora me deixar...

Que tamanha tirania! (REDOL, 1950, p. 135).

Há outra estrofe portuguesa que inspira um batuque do registro de Quixabeira:

Andas morto por saber

Onde eu tenho a minha cama

Tenho-a à borda do rio

Debaixo da verde rama (THOMAZ, 1896, p. 119).

Moça bonita

Não dorme na cama

Dorme na ribeira

Debaixo da rama (DA QUIXABEIRA, 1992).

Por fim, o Samba de Roda Amor de Mamãe (Cachoeira) canta uma quadra muito difundida no Brasil, com diversas versões:

E vem a lua saindo

Por detrás da bananeira

Não é lua, não é nada

É a bandeira brasileira, olha aí (IPHANa, 2006, p. 205).

É uma composição poética muito presente no cancioneiro popular português:

No meio d'aquelle mar

Está uma pedrinha branca

Não é pedra não é nada

É o mar que se levanta (NEVES; CAMPOS, 1893, p. 15).
A incorporação da língua portuguesa pelas expressões rituais afrodescendentes traz consigo uma série de formas de falar, fórmulas poéticas, versos e mesmo estrofes inteiras. São exemplos de conteúdos verbais portugueses que contribuíram para que africanos e seus descendentes atribuíssem sentido à realidade, quando escravizados em terras brasileiras.

\section{A fonte dos sambas}

A forte presença do legado lusitano no samba de roda do Recôncavo Baiano pode ser verificada pela apropriação original de elementos rituais, gêneros musicais (como a chula), expressões dos cantadores (como a "trova") ou instrumentos musicais (como a viola e o pandeiro). Contudo, os exemplos aqui mencionados permitem incluir a influência marcante da poesia tradicional portuguesa, não apenas no idioma, estrofes e ritmos, mas inclusive no "conteúdo verbal" português - ao contrário do que afirma enfaticamente o dossiê elaborado pelo Instituto do Patrimônio Histórico e Artístico Nacional (IPHAN, 2006a).

Um verso muito comum em diversas regiões do Brasil $^{3}$ é cantado pelo Grupo Amor de Mamãe:

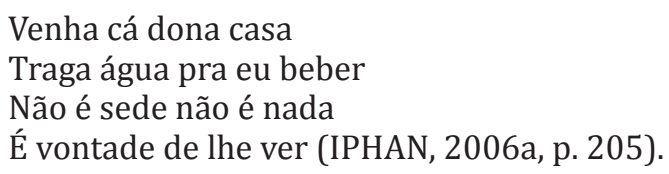

Maria Arminda Zaluar Nunes (1978), estudiosa do cancioneiro português, observa como o tema da água (fonte, rio, regato, ribeira, lagoa ou mar)

Por exemplo em Nhô Belarmino e Nhá Gabriela (1959), Música Popular do Norte (v. 2, 1976), Cocos: alegria e devoção (1999), dentre muitos outros. 
é bastante tradicional na poesia popular lusitana, presente desde a época trovadoresca. Os encontros amorosos entre jovens aconteciam nas fontes ou na beira dos rios, sendo o pedido de água uma espécie de namoro.

Assim, em uma cantiga ao desafio entre uma mulher e um homem, este último provoca:

Entre canas nascem silvas,

Também rosas hão de haver;

Menina que estais na fonte,

Dai-me agua, quero beber (BRAGA, 1869, p. 132).

Parece ser uma metáfora ilustrativa da influência do cancioneiro popular português no samba de roda. Nela, o sambador revela, nas entrelinhas, as fontes de seu canto: as águas portuguesas que beiram o Recôncavo Baiano.

\section{Referências}

BRAGA, Theophilo. Cancioneiro Popular - coligido da tradição. Coimbra: Imprensa da Universidade, 1867.

BRAGA, Theophilo. Cantos Populares do Archipelago Açoriano. Porto: Typographia da Livraria Nacional, 1869.

CAIANA dos Crioulos: ciranda, coco de roda e outros cantos. Memória musical da Paraíba (v. 1). 2003. 1 CD.

CANTADOR de Chula. Direção: Marcelo Rabelo, 2009. 1 DVD.

CASCUDO, Luis da Câmara. Vaqueiros e cantadores. Belo Horizonte: Itatiaia; São Paulo: Editora da USP, 1984

CIA. Cabelo de Maria. Cantos de trabalho. Sesc: 2007. 1 CD.

COCOS: alegria e devoção. Organizado por Maria Ignez Novais Ayala e Marcos Ayala. Natal: EDUFRN, 1999. 1 CD.

CORTESÃO, Jaime. Cancioneiro Popular - antologia precedida dum estudo crítico. Porto: Renascença Portuguesa, 1914.
DA QUIXABEIRA pro berço do Rio. 1992. Disponível em: <http://www.acervoorigens. com/2010/12/da-quixabeira-pro-berco-do-rio-23122010.html>. Acesso em: 02 fev. 2015.

DAMIANA, Dona Dalva. Samba de Roda de Suerdieck. Direção: Francisca Marques. s/d. 1 CD.

FOLCLORE Musical Baiano. Marcus Pereira Discos, 1971. 1 disco sonoro.

IPHAN - Instituto do Patrimònio Histórico e Artístico Nacional. Samba de Roda no Recôncavo baiano. Brasília, 2006a. 213 p.

IPHAN - Instituto do Patrimônio Histórico e Artístico Nacional. Samba de Roda: patrimônio da humanidade. Brasília, 2006b. 1 CD.

ITAPUÃ, Ganhadeiras de. Ganhadeiras de Itapuã. 2015. 1 CD

MÃE Walquíria. Samba e celebração. s/d. 1 CD.

MÚSICA Popular do Norte (v. 2). Marcus Pereira Discos: 1976.

MÚSICA Popular do Sudeste/Centro-Oeste (v. 3). Marcus Pereira Discos: 1974.

NEGA Duda canta os sambas do Recôncavo Baiano. 2008. Disponível em: <https://www. youtube.com/watch?v=wssG917xvs4>. Acesso em: 03 abr. 2016.

NEVES, Cesar das; CAMPOS, Gualdino de. Cancioneiro de Músicas Populares (v. I). Porto: Typographia Occidental, 1893.

NEVES, Cesar das; CAMPOS, Gualdino de. Cancioneiro de Músicas Populares (v. III). Porto: César, Campos e C., 1898.

NHÔ Belarmino e Nhá Gabriela. Mocinhas da Cidade/Paranaguá. RCA Víctor, 1959. 1 disco sonoro.

NOBRE, Cássio. Violas nos sambas do Recôncavo Baiano. Ethnomusicology Review, v. 14, 2009. Disponível em: <http://ethnomusicologyreview.ucla.edu/journal/volume/14/ piece/487>. Acesso em: 20 nov. 2014.

NOGUEIRA, Carlos. Cancioneiro popular de Baião (v. I). 2. ed. Braga: Edições Vercial, 2011 a.

NOGUEIRA, Carlos. Cancioneiro popular de Baião (v. II). 2. ed. Braga: Edições Vercial, 2011b.

NUNES, Maria Arminda Zaluar. O cancioneiro popular em Portugal. Instituto de Cultura Portuguesa/Secretaria de Estado da Cultura/Ministério da Educação e Cultura, 1978 
OLIVEIRA, Francisco Xavier d'Athaide. Romanceiro e cancioneiro do Algarve. Porto: Typographia Universal, 1905.

OUÇA o meu palavreado. Direção: Milton Primo. 2009. Disponível em: <https://www. youtube.com/watch?v=4CngNjecpuo >. Acesso em: 12 maio 2015.

PRATO, Edith do. Vozes da Purificação. Quitanda, 2003. 1 CD.

REDOL, Alves. Cancioneiro do Ribatejo. [S.I.]: Centro Bibliográfico, 1950.

ROMERO, Silvio. Cantos Populares do Brasil (v. 1). Lisboa: Nova Livraria Internacional: 1883. 286 p.

SAMBA Chula de São Braz. Quando eu dou minha risada, há, há. Coordenação e direção artística: Katharina Döring. Direção musical: Cássio Nobre. 2009. 1 CD.

SAMBA Chula de São Braz. Samba Chula de São Braz - Womex 2010 - Clipe ao vivo. Apresentação durante o Festival de Música Womex, em Copenhague, Dinamarca. Disponível em: <https://www.youtube.com/watch?v=Pd9UrChUuZg>. Acesso em: 13 out. 2015.

SAMBA de Nicinha. Raízes de Santo Amaro. Programa Petrobras Cultural, 2012. 1 CD.

SAMBA de Roda no Recôncavo Baiano. Documentário Sonoro do Folclore Brasileiro n. 47. Rio de Janeiro: Minc/Funarte/CFCP, 1994. 1 CD.

SAMBAS de Roda e Candomblés da Bahia. Salvador: JS discos. s/d. 1 disco sonoro.

THOMAZ, Pedro Fernandes. Canções populares da Beira. Figueira: Imprensa Lusitana: 1896.

Recebido em 23/06/2017.

Aceito em 13/01/2018. 